\title{
Examine the Impact of Service Quality on Customer Satisfaction in the Jordanian Mobile Communication Companies
}

\author{
Mosaddad Ihsan Samara \\ Prof. Mohammad Shehada \\ Talal Abu-Ghazaleh University \\ College for Innovation
}

\begin{abstract}
This study intended to examine the impact of service quality on customer satisfaction in mobile communication sector in Jordan. Five dimensions of perceived service quality were used and these are: Tangibility, Reliability, Responsiveness, Assurance and Empathy. Relevant survey data was collected through random convenience sampling using valid questionnaires that distributed online throughout different governorates of Jordan. Several statistical methods were used to test the hypothesis such as Reliability test, Cronbach Alpha, Correlations and Regression analysis. Analysis from a sample of 55 respondents reveals that the Tangibility and Assurance dimensions of perceived service quality did not show a statistically significant relationship with satisfaction, that corporates other dimensions were found to have a positive impact on customer satisfaction, reliability has the most significant influence. In addition, both responsiveness and empathy has the least significant impact on satisfaction.
\end{abstract}

Keywords: Service Quality, Tangibility, Dimensions, SERVQUAL, Telecommunication, Reliability, Responsiveness, Assurance, Empathy.

\section{Introduction}

The management of service quality has gained considerable amount of attention by researchers. The provision of high service quality can provide firms with different benefits and competitive advantage over its competitors (Berry and Thompson, 1982). Service quality is considered essential factor that influence the success and survival of service industries including telecommunication companies. (Parasuraman, Zeithaml \& Berry, 1985). Previous studies have also demonstrated the role of service quality in enhancing customer satisfaction (Newman \& Cowling, 1996; Peterson \& Wilson, 1992; Rust \& Oliver, 1994; Taylor \& Baker, 1994; Kuo, Wu \& Deng, 2009) and its role in leading to favourable financial performance to firms (Al-Hawari, 2006; Black, Briggs, \& Keogh, 2001; Caruana, Money, \& Berthon, 2000; Cheruiyot \& Maru, 2013; Haynes \& Fryer, 2000).

Although previous studies attempted to address service quality in many industries, in different settings, countries and cultures such as Australia (Avkiran, 1994), Turkey (Yavas\&Riecken,1997), India (Angur, Nataraajan\&Jahera, 1999) and the UK (Newman and Cowling, 1996), but to our knowledge, there are limited studies examined the impact of service quality on the telecommunication services in Jordan.

\section{Study Objectives}

With the revolution of telecommunication associated with the new technologies many companies exert much efforts to do the necessary measures of delivering high service quality and providing the best possible service quality which is considered critical in today's highly competitive and global telecommunication environments. (Wang and Hui, 2003). Despite all the efforts that are exerted by mobile telecommunications companies, they faced several obstacles that threaten their continued existence and survival longevity in the market. Which in return, has exacerbated competition in the mobile telecommunication industry because of technological, regulatory and structural changes in the sector. The most significant challenges that have been facing mobile telecommunication businesses may include having: (a) fears of establishing new companies of such type, (b) many advanced markets in many countries, (c) an intensified competition among companies of such type, (d) increase in the needs and wants of consumers, and (e) a rapid technology innovation (Joudeh, J. M., 2017).

The main purpose of the study is to find out the impact of service quality on customer satisfaction in the mobile telecommunications companies in Jordan, Specific objectives of the study are:

1. Achieving better understanding of the relationship between mobile companies and customers.

2. Identifying the impact of the dimensions of service quality upon customers' satisfaction. 


\section{Research Problem}

Focusing on meeting customers' expectations and providing them with a high quality of service can therefore have an impact on the satisfaction and loyalty of customers to their companies. As far as the telecommunication industry is concerned, a relationship between service quality and customer satisfaction has been established. Accordingly, the researchers conducted this study, which aims to examine the impact of service quality on customer satisfaction in the mobile telecommunication industry in Jordan in order to answer the following research questions:

Research question (1): What is the impact of perceived service quality on customer satisfaction in the mobile telecommunication industry?

Research question (2): What is the impact of each dimension of perceived service quality on customer satisfaction in the telecommunication industry?

Research question (3): Are the services provided by mobile telecommunication companies considered adequate and able to fulfil their customers 'needs?

\section{Study Significance:}

Customer satisfaction has traditionally been a crucial criterion for companies pursuing a sustainable competitive advantage. It is very necessary for telecommunications companies in this new millennium to realize that customer satisfaction strategies are the way forward. Therefore, the research aims to allow mobile telecommunications companies in Jordan, to be more constructive and creative in their quality of service and customer satisfaction approaches. It may also help to evaluate and develop policies that would improve their efficiency and effectiveness in their efforts to provide quality of service and satisfy their customers.

\section{Literature Review}

\section{Perceived Service Quality}

In the past two decades, although more and more research findings have appeared concerning quality, it is still worth noting here that there are several distinct conceptualizations of quality (Holbrook, 1994). (Gronroos, 2000) defines service as being a process that consists of a series of more or less of intangible activities that normally, but not necessarily, take place in the interactions occurring between the customer and service employees and/or physical resources or goods and/or systems of the service provider which are provided as solutions to problems concerning customers. Services can be differentiated from manufactured goods in products with respect to four characteristics: Intangibility, heterogeneity, inseparability and perishability (Bateson, 1995). Services are considered "intangible" as their performances are difficult to assess prior to the purchase transaction and their performance is impacted not only by objective performance but also by intangible components of the service experience. Services are "heterogeneous" because they differ between different places, producers and customers, and finally, services are 'inseparable'

Previous research demonstrated the link between service quality and the concepts of perception and expectations (Parasuraman et al., 1985, 1988; Lewis and Mitchell, 1990). The perceptions of service quality formed by customers are considered a consequence of comparing their expectation prior to the service experience with their actual experience with the service, thus, the service will be regarded excellent if perceptions exceed expectations of the customers, it will be considered as good or adequate if it is only equal to the expectations, and will be considered poor, if it does not meet the expectations (Vázquez, 2001).

Based on this perspective, (Parasuraman et al., 1985) developed the SERVQUAL model for the measurement of service quality, and which conceptualizes service quality based on the difference between the received service quality and the expected service quality in relation to five service quality dimensions (Berry, Zeithaml, \& Parasuraman,1990):

(1) Reliability (involves consistency of performance, dependability and accuracy);

(2) Tangibles (includes the physical evidence of the service such as the physical facilities, tools or equipment to the use the service, communication, and appearance of personnel... etc.). Clients often trust the tangible evidence that surrounds the service when making their assessment, as there is no physical element to be assessed in services (Nair et al., 2010);

(3) Responsiveness (concerns the willingness or readiness of employees to help customers and to provide the service promptly);

(4) Empathy (involves access, communication, understanding, attention, caring and individual attention and service is given to the customer) relates to caring and personalized attention paid by the staff to the customers (Gorla, 2011; Ball and Millen, 2003); 
(5) Assurance (involves staff ability to convey confidence, trust, competence, credibility, security and courtesy to customers).

SERVQUAL provides an instrument for measuring functional service quality applicable across a broad range of services (Lam et al., 2004). One of the most central aspects of SERVQUAL is that it is a powerful benchmarking, diagnostic and prescriptive tool (Safiek, 2012). The use of the SERVQUAL approach to measure service quality in service industries is widely accepted; it enables actual measurement of service quality (Ala'aNimer and Ahmad Puad Mat, 2012). The SERVQUAL model has been widely used and served as a framework by academic researchers who sought to examine the service quality more closely in different service industries, cultural contexts, geographic locations and industries (Awan, Shahzad Bukhari \& Iqbal,2011); Chi, Lewis, \& Park, 2003; Sureshchandar, Rajendran, \& Anantharaman, 2003; Wang, Lo, \& Hui, 2003; Yavas, Bilgin, \& Shemwell, 1997). The mobile telecommunication industry was one of the service categories that were used in the development of the original SERVQUAL measurement model and which demonstrated good reliability and validity for the industry (Parasurman et al., 1985; Parasuraman, Berry, \& Zeithaml, 1991). Furthermore, Angur et al. (1999) suggest that the SERVQUAL model is can provide more diagnostic information with respect to the mobile telecommunication sector compared to other measurement service measurement scales.

\section{Customer Satisfaction}

Satisfaction in many research studies has been viewed as an evaluation process or a response to an evaluation process rendered to the consumption experience (Fornell, 1992; Hunt, 1977; Oliver, 1981, 1987). Consumer satisfaction has long been recognized in marketing thought and practice as a central concept as well as an important goal of all business activities (Anderson et al., 1994, Yi, 1990). Oliver (1997) as "the consumer's fulfilment response, the degree to which the level of fulfilment is pleasant or unpleasant", has defined customer satisfaction (p. 28) and has been conceptualized as the consequence of the comparison between what the customers expect and what they actually receive in terms of goods and services (Oliver et al. 1997). If the service performance matches the customers' expectations, then customers will be satisfied, and if the outcomes are lower than expected, then the customers will be dissatisfied (Armstrong \& Kotler, 2014). Therefore, a disparity that occurs between customers' expectations and their perceptions of the outcomes determine the level of customer satisfaction (Rust \& Oliver 2000).

Cronin\& Taylor (1992) emphasize the importance of service quality perceptions and the relationship between service quality and customers' satisfaction. (Luo and Homburg, 2007; Anderson\& Mittal, 2005; Siddqi, 2005; Prabhakaran \& Satya, 2003) revealed that companies should give more attention to raising customers' satisfaction and meeting their needs. They pointed out that successful companies are that companies that are capable of letting the customers feels a certain level of satisfaction in order to maintain their loyalty to them and capable of communicating with them. Satisfaction and perceived value has been suggested to be the direct antecedents of loyalty (Cronin et al, 2000). (Sharma \& Ojha, 2004) define customer satisfaction as a feeling of happiness or disappointment results from comparing product performance and consumer expectations. Customers' satisfaction refers to the discrepancies occurring between the customers' expectations and the performance of the product / service creating a disconfirmation (Oliver, 1980).

According to the level of specificity satisfaction has been conceptualized differently (Yi, 1990) and at least two different measurements can be distinguished in the marketing literature; transaction-specific and cumulative (Boulding et al., 1993; Johnson et al., 1995; Andreassen, 2000; Kalra, Staelin \& Zeithaml, 1993). On the one hand, from a transaction specific perspective customer satisfaction is viewed as a post- choice evaluative judgment or an affective reaction to a specific purchase occasion and referring to the most recent transactional experience (Hunt 1977; Oliver 1977, 1980, 1993). Up until now, behavioural researchers have developed a rich body of literature focusing on the antecedents and consequences of this type of customer satisfaction at the individual level (Yi 1990). In contrast, a cumulative perspective views satisfaction as "an over- all evaluation based on the total purchase and consumption experience with a good or service over time" (Fornell, 1992; Johnson and Fornell 1991; Anderson et al., 1994a, b; Fornell, and Lehmann 1994, p. 54). According to Oliver (1993), consumer satisfaction is a result of positive or negative emotional responses and cognitive dissonance, and the level of satisfaction is determined by the difference after comparing the expectations for the functions before purchase and the actual experience of these functions after purchase. While transaction specific definitions could provide specific diagnostic information about a product or service, cumulative satisfaction is a more essential indicator of a business's current and future performance, and it is cumulative satisfaction that motivates a business to investment in customer satisfaction (Anderson et al., 1994). Therefore, the current study conceptualises satisfaction as an evaluation process with respect to a cumulative consumption experience. 
Customer satisfaction and customer is becoming increasingly important in the context of industries characterized by intense competition and slow growth demands more attention of firms (Juhl, Kristensen \& Ostergaard). Satisfaction in previous literature has been demonstrated as an antecedent to positive outcomes such as enhancing intentions to repeatedly purchase a product or service (Taylor \& Baker, 1994), communicating positive word of mouth (Reynolds, Beatty, 1999) and two aspects of customer share; share-of-purchase and share-of-visits (Mägi, 2003). Previous studies have also provided evidence for the strong positive relationship between satisfaction and customer loyalty (Juhl et al., 2002; Reynolds, Beatty, 1999).

\section{Research Model and Hypothesis:}

The study's model as shown in (Fig. 1) focuses on the relationship between the different dimensions of service quality and satisfaction. More precisely, the framework examines the effect of five dimensions of service quality defined by Parasuraman et al. (1985): tangibility, reliability, responsiveness, assurance, empathy, and aims to investigate the impact of these dimensions in the mobile telecommunications industry.

\section{Independent Variables Dependent Variable}

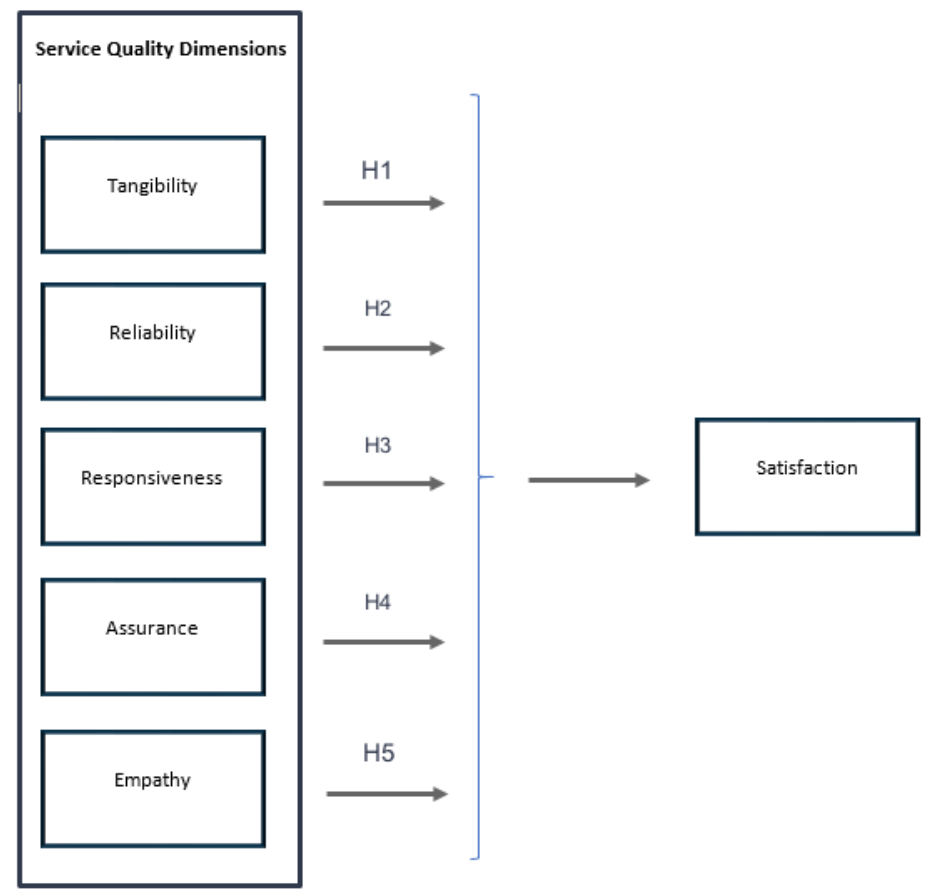

Figure (1): Research Model

Hypothesis H1: Tangibility has an impact on customer satisfaction at the Telecommunication companies in Jordan at $(0=0.5)$.

Hypothesis H2: Reliability has an impact on customer satisfaction at the Telecommunication companies in Jordan at $(0=0.5)$.

Hypothesis H3: Responsiveness has an impact on customer satisfaction at the Telecommunication companies in Jordan at $(0=0.5)$.

Hypothesis H4: Assurance has an impact on customer satisfaction at the Telecommunication companies in Jordan at $(0=0.5)$.

Hypothesis H5: Empathy has an impact on customer satisfaction at the Telecommunication companies in Jordan at $(0=0.5)$.

\section{Research Methodology:}

\section{Sampling Design and Data Collection}

The population sample for this study consisted of the mobile telecommunication customers in Jordan with more than 6 million people. There are 3telecommunication Companies (Orange, Zain \&Umniah) in Jordan. The study used a 
random and convenience sample and the information was obtained through personal contacts. An online link of the questionnaire was sent to the respondents, and the participation in the study was voluntary.

A total of 55valid responses were obtained from the survey. Based on the collected data, a demographic profile of the respondents was constructed as shown in (Table. 1). The sample included 60\% female and 40\% male respondents. Various age groups were presented in the sample but most respondents were ranging from 18 to 38 years old. Marital status and household composition categories range $38.2 \%$ for married and 61.8 for single. In addition, the sample demographic profile included the governorate with $87.3 \%$ for Amman, education with a highest percentage of $70.9 \%$ for bachelor degree and $20 \%$ for master and $\mathrm{PhD}$ degrees. Whereas, for the type of mobile service line a percent of $63.6 \%$ for 'pay as you go card' and $36.4 \%$ for post-paid lines, and concerning the mobile line service provider/ operator for Zain $52.7 \%$, Orange $20 \%$ and Umniah $27.3 \%$.

Table 1: Sample profile.

\begin{tabular}{|l|l|l|}
\hline Characteristic & Category & $\%$ \\
Gender & Female & 60.0 \\
& Male & 40.0 \\
& $18-28$ years' old & 49.1 \\
Marital Status & $29-38$ years' old & 36.4 \\
Governorate & $39-48$ years' old & 9.1 \\
& $49-58$ years' old & 5.5 \\
& Over 58 years old & 0.0 \\
Monthly income & Married & 38.2 \\
& Single & 61.8 \\
Type of mobile line & Amman & 87.3 \\
Mobile line operator & Irbid & 5.5 \\
& Zarqa & 5.5 \\
& Other & 1.8 \\
& Less than 200 JDs & 7.3 \\
& 200-449 JDs & 18.2 \\
& 500-799 JDs & 21.8 \\
& 800-1099 JDs & 9.1 \\
& 1100-1399 JDs & 1.8 \\
& More than 1400 JDs & 41.8 \\
& Secondary school & 1.8 \\
& degree & 3.6 \\
& Low Diploma degree & 3.6 \\
& High Diploma & 70.9 \\
& Bachelor's degree & 20.0 \\
& Master or PhD degree & \\
& Card (pay as you go) & 63.6 \\
& Post-paid & 36.4 \\
& Zain & 52.7 \\
& Orange & 20.0 \\
& Umniah & 27.3 \\
\hline
\end{tabular}

\section{Constructs and Measures}

All measurement scales used in this study are selected from previous studies. Service quality was measured using the original SERVQUAL questions developed by Parasuraman et al. (1985) for all attributes of service quality. As tangibility dimension was measured using 4 item scale questions, reliability 5 items, responsiveness 4 items, assurance 4 items, and 5 items for the empathy attribute. Customer satisfaction was measured by eight scale items adapted from (Fornell, Johnson, Anderson, Cha \& Bryant, 1996; Lai, Griffin \&Babin, 2009; Dahiyat, Akroush\& Abu-Lail, 2011). All dimensions were measured using a 5-point Likert scale ranging from 0 (strongly disagree) to 5 (strongly agree). (Table. 2) shows the items for each construct. 


\section{Reliability:}

Prior to testing our hypotheses, the scales were tested for internal consistency by using Cronbach Alpha and it is found that, as shown in (Table. 2), that the value of tangibility is $0.817,0.800$ for reliability, 0.845 for responsiveness, 0.865 for assurance and 0.923 for satisfaction and all of these indicate adequate reliability of all research constructs since Cronbach alpha value for each measured construct is $>0.70$.

Case Processing Summary

\begin{tabular}{|c|c|c|c|}
\hline & & $\mathbf{N}$ & $\%$ \\
\hline Cases & Valid & 55 & 100.0 \\
\hline & Excluded $^{\mathrm{a}}$ & 0 & .0 \\
\hline & Total & 55 & 100.0 \\
\hline $\begin{array}{l}\text { a. Lis } \\
\text { procec } \\
\text { Reliab }\end{array}$ & $\begin{array}{l}\text { wise deletio } \\
\text { lure. } \\
\text { ility Statisti }\end{array}$ & sed & ariabl \\
\hline Cront & ach's Alpha & N & \\
\hline .887 & & 6 & \\
\hline
\end{tabular}

Table 2:Scale items for construct measures.

\section{Descriptive and Normality}

The results of descriptive and normality test as shown in the tables below:

Case Processing Summary

\begin{tabular}{|l|l|l|l|l|l|}
\hline \multicolumn{5}{|l|}{ Cases } & \multicolumn{4}{l|}{ Missing } & Total \\
\hline Valid & Percent & $\mathbf{N}$ & Percent & $\mathbf{N}$ & Percent \\
\hline $\mathbf{N}$ & $100.0 \%$ & 0 & $0.0 \%$ & 55 & $100.0 \%$ \\
\hline 55 & & & & \\
\hline
\end{tabular}

\section{Descriptive Statistics}

\begin{tabular}{|l|l|l|l|l|l|l|l|}
\hline & N & Minimum & Maximum & Mean & Std. Deviation & Skewness & Skewness \\
\cline { 2 - 8 } & Statistic & Statistic & Statistic & Statistic & Statistic & Statistic & Std. Error \\
\hline SQ_T & 55 & 2.14 & 5.00 & 3.7793 & .58782 & -.062 & 322 \\
Tang_T & 55 & 2.00 & 5.00 & 3.9273 & .65559 & -.514 & .322 \\
Rel_T & 55 & 2.00 & 5.00 & 3.7164 & .66074 & -.124 & 322 \\
Resp_T & 55 & 1.00 & 5.00 & 3.6818 & .82979 & -.890 & .322 \\
Assur_T & 55 & 1.00 & 5.00 & 3.8818 & .71176 & -1.039 & .322 \\
Empth_T & 55 & 1.00 & 5.00 & 3.7200 & .71761 & -.702 & 322 \\
Sats_T & 55 & 2.00 & 5.00 & 3.9750 & .69738 & -.776 & .322 \\
Valid N (listwise) & 55 & & & & & & \\
\hline
\end{tabular}

\section{Findings:}

To test the relationship between the perceived service quality dimensions and customer satisfaction, multiple regression was conducted as shown in (Table. 3). The results show that the relationship between reliability and satisfaction is significant, and that it is a strong positive relationship $(\beta=0.677, \mathrm{t}=4.451, \mathrm{p}<.001)$ and therefore lending support to accept hypothesis H2. The results also showed a positive but weaker relationship between responsiveness and satisfaction $(\beta=0.425, \mathrm{t}=2.525, \mathrm{p}<.05)$ as well empathy and satisfaction $(\beta=0.425, \mathrm{t}=2.525, \mathrm{p}<.05)$ which accept hypothesis $\mathrm{H} 3$ and $\mathrm{H} 5$. On the other hand, the results showed that the relationship between tangibility and satisfaction was not significant $(\beta=.128, \mathrm{t}=1.057, \mathrm{p}=.296)$, and that the relationship between satisfaction and assurance is not significant $(\beta=.244, \mathrm{t}=1.350, \mathrm{p}=.183)$ so that we reject hypothesis $\mathrm{H} 1$ and $\mathrm{H} 4$. Based on these results, we accept the alternative Hypothesis $\mathrm{H} 2, \mathrm{H} 3$ and $\mathrm{H} 5$, and reject the alternative Hypothesis $\mathrm{H} 1$ and $\mathrm{H} 4$. 
Table 3: Multiple regression of customer satisfaction.

\begin{tabular}{llll}
\hline Predictor & $\begin{array}{l}\text { Unstandardized } \\
\text { coefficient }\end{array}$ & $\begin{array}{l}\text { Standardized } \\
\text { Coefficients }(\boldsymbol{\beta})\end{array}$ & $\boldsymbol{t}$-value \\
Tangibility & 0.136 & 0.128 & 1.057 \\
Reliability & 0.715 & 0.677 & $4.451^{* *}$ \\
Responsiveness & 0.357 & 0.425 & 2.525 \\
Assurance & 0.239 & 0.244 & $1.350^{*}$ \\
Empathy & 0.376 & 0.386 & $2.256^{*}$ \\
\hline
\end{tabular}

$* p<.05 \overline{* * p}<.001$

Model Summary

\begin{tabular}{ll|lll} 
Model & R & R Square & $\begin{array}{l}\text { Adjusted } \\
\text { Square }\end{array}$ & $\begin{array}{c}\text { RStd. Error of } \\
\text { the Estimate }\end{array}$ \\
\hline 1 & $.763^{\text {a }}$ & .583 & .540 & .47287 \\
\hline
\end{tabular}

a. Predictors: (Constant), Empth_T, Tang_T, Rel_T, Resp_T, Assur_T

ANOVA ${ }^{\mathrm{a}}$

$\begin{array}{lllll}\text { Model } & \text { Sum of Squares df } & \text { Mean Square } & \text { F } & \text { Sig. }\end{array}$

\begin{tabular}{lllllll}
\hline 1 & Regression & 15.306 & 5 & 3.061 & 13.690 & .000
\end{tabular}

\begin{tabular}{l|l|l|l|l|l}
\hline Residual & 10.957 & 49 & .224 & \\
\hline Total & 26.263 & 54 & & \\
\hline
\end{tabular}

a. Dependent Variable: Sats_T

b. Predictors: (Constant), Empth_T, Tang_T, Rel_T, Resp_T, Assur_T

Coefficients $^{\mathrm{a}}$

\begin{tabular}{|c|c|c|c|c|c|c|}
\hline & & Unsta & ed Coefficients & $\begin{array}{l}\text { Standardized } \\
\text { Coefficients }\end{array}$ & & \\
\hline Model & & B & Std. Error & Beta & t & Sig. \\
\hline 1 & (Constant) & .843 & .462 & & 1.824 & .074 \\
\hline & Tang_T & .136 & .129 & .128 & 1.057 & .296 \\
\hline & Rel_T & .715 & .161 & .677 & 4.451 & .000 \\
\hline & Resp_T & .357 & .141 & .425 & 2.525 & .015 \\
\hline & Assur_T & .239 & .177 & .244 & 1.350 & .183 \\
\hline & Empth_T & .376 & .166 & .386 & 2.256 & .029 \\
\hline
\end{tabular}

\section{Limitations:}

Dependent Variable: Sats_T

Several limitations of the study should be noted:

- The scope of the research is limited because the sample size is small. The response rate is also relatively low. Therefore, the results may not be entirely applicable in other contexts and caution should be taken in generalizing the findings.

- The study has not been carried out for all governorates in Jordan; hence, the results are not necessarily generalizable for the whole country.

Conclusion:

This research explores a model that combines service quality dimensions and satisfaction. The perceived service quality directly affects customer satisfaction among mobile operators ' telecommunications customers, the following conclusions can be derived from the interpretation of the research results:

Service quality dimensions: Reliability, Responsiveness and Empathy had significant positive impact on satisfactions, while Tangibility and Assurance did not have a significant relationship with satisfaction.

\section{Recommendations:}

The findings of the study can determine the recommendations desired. Achieving Tangibility can be achieved through modern-techniques, visual appealing facilities and materials associated with service, communication and neat appearing of personnel. In addition, the Assurance dimension could be done through strengthening the values of convey confidence, trust, competence, credibility, security and courtesy to customers. Therefore, that service quality can be improved and in return, customers will be more satisfied. 


\section{Future Studies:}

Future studies should consider the following:

- Extending the scope of the analysis especially, the number of customers. Therefore, it would be better to increase the sample size.

- Enhancing the research findings and future inquiries with more diverse geographic locations.

- Furthermore, Demographic variables could be examined and relevant moderators could be incorporated in the model to assess their impact on the relationship between service quality dimensions and satisfaction.

- Replication of this study can be useful for more validity and consistency.

\section{References:}

Al-Momani, K., Noor, M., \&Azila, N. (2009), "E-service quality, ease of use, usability and enjoyment as antecedents of E-CRM performance: An empirical investigation in Jordan Mobile Phone Services", The Asian Journal of Technology Management, 2(2), 50-64.

Al-Hawari, M., \& Ward, T. (2006), "The effect of automated service quality on Australian banks' financial performance and the mediating role of customer satisfaction", Marketing Intelligence \& Planning, 24(2), 127-147.

Awan, H., Shahzad Bukhari, K., \& Iqbal, A. (2011), "Service quality and customer satisfaction in the banking sector: A comparative study of conventional and Islamic banks in Pakistan", Journal of Islamic Marketing, 2(3), 203224.

Cheruiyot, T., \& C. Maru, L. (2013),"Service quality and relative performance of public universities in East Africa”, The TQM Journal, 25(5), 533-546.

Cudjoe, A. G., Anim, P. A., \& George, A. A. (2015), 'Effect of customers' satisfaction of service delivery on customers' retention of tigo telecommunication network (A Case of Abokobi-Madina Locality)", The International Journal of Business \& Management, 3(1), 146.

Haddad, A. E., Al-Dmour, H., \& Al-Zu'bi, Z. M. F. (2012), "Perceived service quality and customer satisfaction: an empirical investigation of the rebranded telecommunication companies in Jordan", European Journal of Social Sciences, 34(1), 118-137.

Joudeh, J. M. (2017), "The Impact of Service Quality Dimensions upon Customers' Satisfaction: An Empirical Study Applied in the Jordanian Mobile Telecommunication Sector", International Review of Management and Business Research, 6(1), 184.

Kuo, Y. F., Wu, C. M., \& Deng, customer satisfaction, and post-purchase intention in mobile value-added services",Computers in Human Behavior W. J. (2009) "The relationships among service quality, perceived value, , 25(4), 887-896.

Lai, F., Griffin, M., \&Babin, B. J. (2009), "How quality, value, image, and satisfaction create loyalty at a Chinese telecom”, Journal of Business Research, 62(10), 980-986.

Oyeniyi, O., \&Abiodun, A. J. (2011), "Service Quality, Value Offer, Satisfaction and Loyalty: an Empirical Relationship in the Nigerian Telecom Industry",Journal of Contemporary Management Research, 5(2).

Parasuraman, A., Berry, L. L., \&Zeithaml, V. A. (1991), "Refinement and reassessment of the SERVQUAL scale", Journal of Retailing, 67(4), 420.

Rahhal, W. (2015), "The effects of service quality dimensions on customer satisfaction: An empirical investigation in Syrian mobile telecommunication services",International Journal of Business and Management Invention, 4(5), 81-89.

S. Alnsour, M., Abu Tayeh, B., \& Awwad Alzyadat, M. (2014), "Using SERVQUAL to assess the quality of service provided by Jordanian telecommunications sector", International Journal of Commerce and Management, 24(3), 209-218. 